\title{
Relationship of body mass index with bone mineral density in postmenopausal women: an Indian perspective
}

\author{
Avani Goyal*, Veena Ganju Malla
}

Department of Obstetrics and Gynecology, Post Graduate Institute of Medical Education and Research, Dr. Ram Manohar Lohia Hospital, New Delhi, India

Received: 02 July 2019

Revised: 08 September 2019

Accepted: 13 September 2019

*Correspondence:

Dr. Avani Goyal,

E-mail: avani.goyal@yahoo.com

Copyright: () the author(s), publisher and licensee Medip Academy. This is an open-access article distributed under the terms of the Creative Commons Attribution Non-Commercial License, which permits unrestricted non-commercial use, distribution, and reproduction in any medium, provided the original work is properly cited.

\section{ABSTRACT}

Background: Osteoporosis is a common health problem that affects postmenopausal females, leading to increased susceptibility to fractures. Body mass index (BMI) has been shown to be an important predictor of bone mineral density (BMD) with increased body weight correlating with positive influence on bone metabolism. Low BMI predisposes postmenopausal females to rapid bone loss and low bone mass, crucial in the pathogenesis of osteoporosis. However, a specific BMI value chart to accurately predict osteoporosis remains to be fully established. The present study aimed to investigate the relationship of BMI and BMD in postmenopausal Indian females.

Methods: 90 healthy postmenopausal females with 1-5 years of menopause were enrolled in the study. Subjects were categorized according to their BMI into normal, overweight and obese. BMD was assessed using dual energy X-ray absorptiometry (DEXA) scan at L1-L4 vertebrae and femoral neck and expressed as T-scores. Quantitative variables were compared using ANOVA/Kruskal Wallis Test.

Results: Bone mineral density was significantly higher in the obese group as compared to normal BMI group at both lumbar spine $(\mathrm{p}=0.001)$ and femoral neck $(\mathrm{p}=0.001)$. BMD at lumbar spine was lower than that at femoral neck across all the three groups of BMI.

Conclusions: BMI and body weight are important factors affecting BMD. Postmenopausal females with low BMI are more likely to have osteopenia and osteoporosis and are thus at an increased risk of pathological fractures. Routine BMD monitoring in postmenopausal females with low BMI may be necessary to initiate early clinical interventions for osteoporosis.

Keywords: Body mass Index, Dual Energy X-ray absorptiometry, Menopause, Oseoporosis

\section{INTRODUCTION}

Natural menopause is the occurrence of twelve consecutive months of amenorrhea, for which no other obvious pathological or physiological cause is recognized. ${ }^{1}$ According to Indian Menopausal Society average age of menopause is 47.5 years in Indian women with an average life expectancy of 71 years. $^{2}$
The projected figures for population of India in 2026 is estimated to be 1.4 billion, with 173 million people, over the age of 60 years and 103 million to be of menopausal population. With this tremendous rise in postmenopausal female population, menopausal health is an issue of growing concern. Among most of the postmenopausal changes, decreasing bone density leads to a great amount of morbidity in the form of pathological fractures. Thirty 
five to forty percent of women between 40 and 65 years of age have been detected with osteopenia whereas 8$30 \%$ suffers from osteoporosis. Every female over 65 years of age have been found to have either osteopenia or osteoporosis. $^{3}$

Studies have reported that Asian women have higher predisposition for osteoporosis than their Caucasian counterparts. ${ }^{4}$ The attainment of peak bone mass in adolescent years and the rate of bone loss during postmenopausal years are the major factors contributing to bone health in elderly females. ${ }^{5}$

Peak bone mass is achieved in the early 20's of life. Beyond the age of 30 years, trabecular bone resorption begins to exceed bone formation by about $0.7 \%$ per year. Bone loss accelerates after menopause, as up to $5 \%$ of trabecular bone and $1-1.5 \%$ of total bone mass loss occurs per year. This accelerated bone loss occurs mostly in the first five years after menopause. Bone loss decreases after first five years but continues as aging related loss. ${ }^{6}$

A major cause of this declining bone mass in postmenopausal females is the deficiency in estrogen level that occurs after menopause. Estrogen has been established to be an important determinant of bone health. It has protective effect on bone mineralization directly and indirectly through various mechanisms and thus limits bone resorption and helps in increasing the net bone mass. Estrogen has a direct effect on osteoclasts through its receptors ER $\alpha$ and ER $\beta$ and also can inhibit osteoclast stimulatory factor and enhance release of osteoclast inhibitory factors. It modulates production of bone resorption factors like interleukin 1 and 6 , tumor necrosis factor alpha and beta. It has been shown to promote the apoptosis of osteoclast and inhibits the apoptosis of osteoblast through non genomic mechanisms. Estrogen also increases the vitamin D receptors on osteoblasts. ${ }^{6,7}$ Thus, the protective effect of estrogen reverses following menopause, leading to an increased bone loss. The circulating levels of estradiol after menopause is approximately $10-20 \mathrm{pg} / \mathrm{ml}$, in comparison to its premenopausal level of $40-400 \mathrm{pg} / \mathrm{ml}$. Estrogen level over $40 \mathrm{pg} / \mathrm{ml}$ exerts protective effect on bone whereas levels below $20 \mathrm{pg} / \mathrm{ml}$ predispose to increased bone loss. ${ }^{8}$

Another mechanism which comes into play after menopause is the peripheral aromatization of androstenedione in the adipose tissue, which is the major source of estrogen. Androgen secretion occurs mainly from the adrenals and ovaries. Ovarian secretion of androgen continues beyond menopause due to sparing of the stromal component, which is then converted to estradiol. $^{6}$

BMI is used to classify various degree of adiposity and measures body composition more accurately than weight alone. Obesity affects many sequelae of menopause including bone mineral density. Various other mechanisms by which obesity affects bone mineral density are decreased sex-hormone binding globulin which increases the concentration of free sex steroids, increasing levels of serum leptin, increasing synthesis of insulin like growth factors in the liver and the skeleton, hyperinsulinemia and insulin resistance. Increased body mass also increases weight bearing on the muscles that stimulates bone formation. ${ }^{9}$

The current gold standard investigative technique for osteoporosis is dual energy X-ray absorptiometry (DEXA) scan, used to examine the bone mass of total hip, femoral neck, lumbar spine, or whole body. The current study measured the bone mineral density by dual energy X-ray absorptiometry (DEXA) scan at hip and lumbar spine in postmenopausal women of different body mass index (keeping other factors constant) and analyzed their relationship with each other. Thus, by early detection of low bone density in postmenopausal women it might be possible to reduce the impact of osteoporosis.

\section{METHODS}

This observational cross sectional study was conducted at Post Graduate Institute of Medical Education and Research, Dr. Ram Manohar Lohia Hospital, New Delhi, India from $1^{\text {st }}$ November 2016 to $31^{\text {st }}$ March 2018 with a sample size of 90 postmenopausal females. Women with natural menopause of one to five year duration were included in the study. Women with known case of hyperthyroidism, hyperparathyroidism, diabetes mellitus, renal or liver disease, rheumatoid arthritis; women on medications like levothyroxine, furosemide, heparin, phenytoin, phenobarbital, vitamin $\mathrm{K}$, ranitidine, calcium carbonate, vitamin D3, and corticosteroid; women on hormone replacement therapy; women with history of chronic alcohol consumption and smoking; women with surgical menopause were excluded to rule out other causes of low bone density.

A detailed history including demographic details on educational qualification, income, occupation, diet and exercise schedule was obtained. Medical, obstetrical, menstrual, and drug intake history was collected using a structured questionnaire from each subject. A complete general physical, systemic and gynaecological examination was performed on each subject. Estimation of thyroid, parathyroid, liver and kidney function tests, blood sugar level and vitamin D level was done. Patients were recruited in the study based on the results of these tests. Informed written consent was obtained from each subject before enrollment.

Weight was measured after removing shoes and wearing light weight clothes using electronic weighing machine. Height was measured by wall mounted stadiometer with a least count of $1 \mathrm{~mm}$. BMI was calculated using formula BMI $\left(\mathrm{kg} / \mathrm{m}^{2}\right)=$ Weight (in $\mathrm{kg}$ ) $/$ height $^{2}$ (in meter). Patients were categorized according to their body mass index into 
3 groups: normal (BMI 18.5-24.9kg/m²), overweight (BMI $25.0-29.9 \mathrm{~kg} / \mathrm{m}^{2}$ ) and obese $\left(\right.$ BMI $\geq 30.0 \mathrm{~kg} / \mathrm{m}^{2}$ ), with each group comprising of 30 subjects.

All the subjects underwent dual energy X-ray absorptiometry scan at L1-L4 lumbar spine and femoral neck using DEXA machine. The model of DEXA machine used was HOLOGIC 010-1547 manufactured by HOLOGIC inc, Bedford, MA, USA, software version 13.0:5.

\section{Statistical analysis}

Observed BMD values were expressed as T-scores. T score is the bone mineral density (BMD) at the site when compared to the young normal reference mean. It is a comparison of a patient's BMD to that of a healthy 30year-old. WHO has classified bone mineral density according to the $\mathrm{T}$ score into the following groups: Normal ( $\mathrm{T}$ score -1.0 and above); Osteopenia ( $\mathrm{T}$ score between -1.0 and -2.5); Osteoporosis ( $\mathrm{T}$ score -2.5 and below). The subjects in the present study were categorized according to the WHO criteria for BMD. Outcome was to compare the bone mineral density in postmenopausal women of different groups of body mass index.

Categorical variables were presented in number and percentage $(\%)$ and continuous variables were presented as mean $\pm \mathrm{SD}$ and median. Normality of data was tested by Kolmogorov-Smirnov test. Non parametric test was used wherever the normality was rejected. Quantitative variables were compared using ANOVA/Kruskal Wallis Test (when the data sets were not normally distributed) between the three groups. Qualitative variables were correlated using Chi-Square test. Multivariate ordinal regression was used to assess the significant factors affecting BMD. A $p$ value of $<0.05$ was considered statistically significant. The data was entered in MS EXCEL spreadsheet and analysis was done using Statistical Package for Social Sciences (SPSS) version 21.0.

\section{RESULTS}

Among the total 90 study subjects the mean age was $52.54 \pm 3.19$ years. The mean age at menopause was $49.87 \pm 2.29$ years for the population studied. The mean duration of menopause was $2.71 \pm 1.41$ years (Table 1 ). The biochemical parameters of all the study subjects were kept within normal range so as to exclude any other factor which may affect bone density of the study subjects.

Among the total study subjects $(\mathrm{n}=90), 22(24 \%)$ females had T-scores at lumbar spine above -1.0, 44 (49\%) females had T-scores between -1.0 and -2.5 and 24 (27\%) females had T-scores below -2.5 (Figure 1). The present study reveals a statistically significant relationship between body mass index and bone mineral density at lumbar spine. The frequency of osteoporosis and osteopenia were $50 \%$ and $43.33 \%$ respectively in females with normal BMI whereas it was $16.67 \%$ and $40 \%$ in females with BMI $>30 \mathrm{~kg} / \mathrm{m}^{2}$. Normal BMD was observed in $43.33 \%$ obese, $23.33 \%$ of overweight and only $6.67 \%$ of normal BMI postmenopausal females. Bone mass was thus observed to be better in obese postmenopausal females (Table 2). This is also depicted by graphical representation.

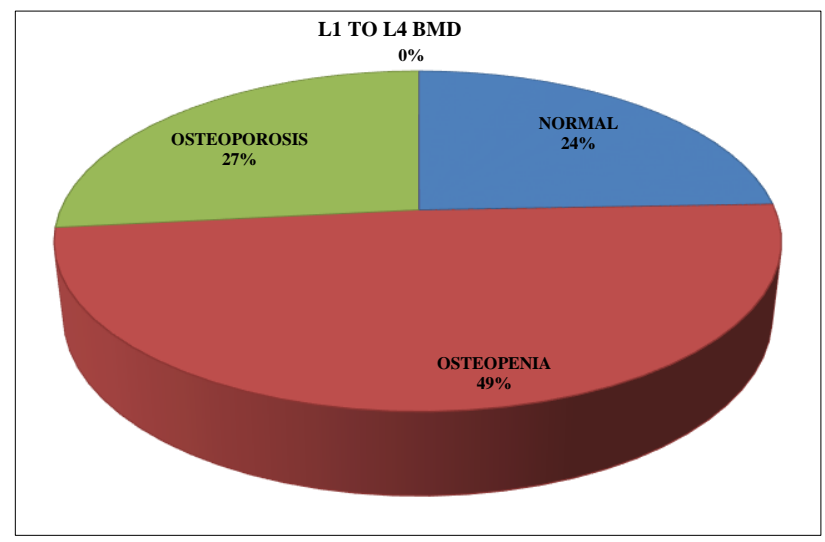

Figure 1: Distribution of bone mineral density at lumbar spine amongst all study subjects $(n=90)$.

Table 1: Descriptive data of all study subjects $(n=90)$.

\begin{tabular}{|lll|}
\hline Patient characteristic & $\begin{array}{l}\text { Sample } \\
\text { size }\end{array}$ & Mean \pm SD \\
\hline Age (years) & 90 & $52.54 \pm 3.19$ \\
\hline Age at menopause (years) & 90 & $49.87 \pm 2.29$ \\
\hline Menopausal duration (years) & 90 & $2.71 \pm 1.41$ \\
\hline Height $(\mathrm{cm})$ & 90 & $153.94 \pm 7.07$ \\
\hline Weight $(\mathrm{kg})$ & 90 & $65.24 \pm 11.78$ \\
\hline BMI $\left(\mathrm{kg} / \mathrm{m}^{2}\right)$ & 90 & $27.44 \pm 4.1$ \\
\hline
\end{tabular}

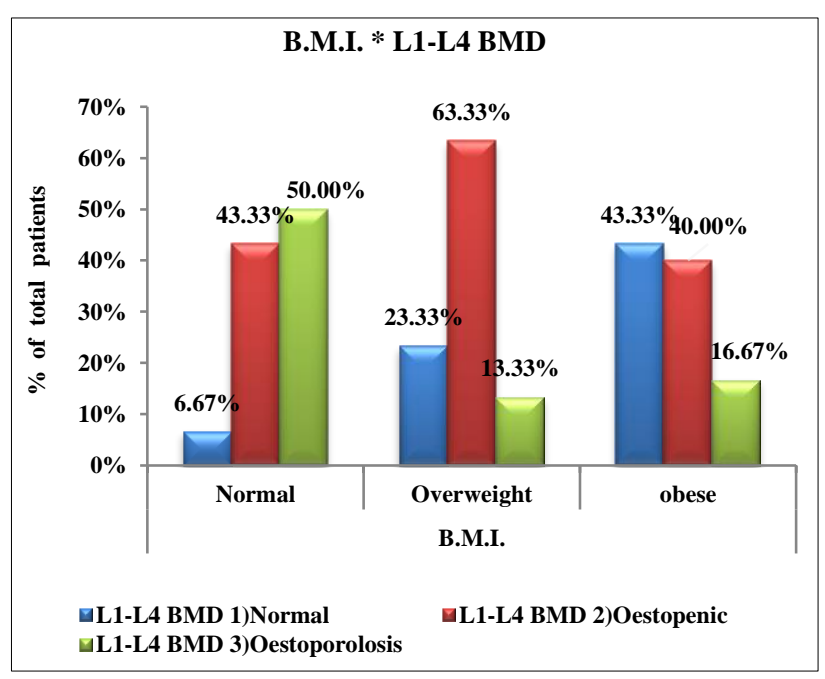

Figure 2: Depicting relationship of BMI and BMD at lumbar spine. 
Table 2: Relationship of BMD at L1to L4 lumbar spine to all three categories of BMI of early postmenopausal females.

\begin{tabular}{|c|c|c|c|c|c|c|}
\hline & & \multicolumn{3}{|c|}{$\begin{array}{l}\text { No. of subjects with T score at lumbar spine } \\
\text { in the range }\end{array}$} & \multirow{2}{*}{$\begin{array}{l}\text { Total no. of } \\
\text { subjects }\end{array}$} & \multirow{2}{*}{ P value } \\
\hline & & $\begin{array}{l}\text { Normal } \\
(\geq \mathbf{- 1 . 0})\end{array}$ & $\begin{array}{l}\text { Osteopenia } \\
(-1.0 \text { to }-2.5)\end{array}$ & $\begin{array}{l}\text { Osteoporosis } \\
(\leq-2.5)\end{array}$ & & \\
\hline \multirow{3}{*}{ B.M.I. } & Normal $\left(18.5-24.9 \mathrm{~kg} / \mathrm{m}^{2}\right)$ & $2(6.67 \%)$ & $13(43.33 \%)$ & $15(50.00 \%)$ & $30(100.00 \%)$ & \multirow{3}{*}{$0.001 *$} \\
\hline & Overweight $\left(25.0-29.9 \mathrm{~kg} / \mathrm{m}^{2}\right)$ & $7(23.33 \%)$ & $19(63.33 \%)$ & $4(13.33 \%)$ & $30(100.00 \%)$ & \\
\hline & Obese $\left(\geq 30.0 \mathrm{~kg} / \mathrm{m}^{2}\right)$ & $13(43.33 \%)$ & $12(40.00 \%)$ & $5(16.67 \%)$ & $30(100.00 \%)$ & \\
\hline
\end{tabular}

*Statistically significant.

Table 3: Relationship of BMD at femoral neck to all three categories of BMI of early postmenopausal females.

\begin{tabular}{|c|c|c|c|c|c|c|}
\hline & & \multicolumn{3}{|c|}{$\begin{array}{l}\text { No. of subjects with } \mathrm{T} \text { score at femoral neck } \\
\text { in the range }\end{array}$} & \multirow{2}{*}{$\begin{array}{l}\text { Total no. of } \\
\text { subjects }\end{array}$} & \multirow{2}{*}{ P value } \\
\hline & & $\begin{array}{l}\text { Normal } \\
(\geq-1.0)\end{array}$ & $\begin{array}{l}\text { Osteopenia } \\
(-1.0 \text { to }-2.5)\end{array}$ & $\begin{array}{l}\text { Osteoporosis } \\
(\leq-2.5)\end{array}$ & & \\
\hline \multirow{3}{*}{ B.M.I. } & Normal $\left(18.5-24.9 \mathrm{~kg} / \mathrm{m}^{2}\right)$ & $5(16.67 \%)$ & $15(50.00 \%)$ & $10(33.33 \%)$ & $30(100.00 \%)$ & \multirow{3}{*}{$0.001 *$} \\
\hline & Overweight $\left(25.0-29.9 \mathrm{~kg} / \mathrm{m}^{2}\right)$ & $13(43.33 \%)$ & $16(53.33 \%)$ & $1(3.33 \%)$ & $30(100.00 \%)$ & \\
\hline & Obese $\left(\geq 30.0 \mathrm{~kg} / \mathrm{m}^{2}\right)$ & $14(46.67 \%)$ & $15(50.00 \%)$ & $1(3.33 \%)$ & $30(100.00 \%)$ & \\
\hline
\end{tabular}

*Statistically significant.

Table 4: Mean BMD at femoral neck and lumbar spine across the three categories of BMI representing higher BMI at femoral neck with respect to lumbar spine.

\begin{tabular}{|c|c|c|c|c|}
\hline & $\begin{array}{l}\text { Normal BMI }\left(18.5-24.9 \mathrm{~kg} / \mathrm{m}^{2}\right) \\
(\mathrm{n}=30)\end{array}$ & $\begin{array}{l}\text { Overweight }\left(25.0-29.9 \mathrm{~kg} / \mathrm{m}^{2}\right) \\
(\mathrm{n}=30)\end{array}$ & $\begin{array}{l}\text { Obese }\left(\geq 30.0 \mathrm{~kg} / \mathrm{m}^{2}\right) \\
(\mathrm{n}-30)\end{array}$ & $P$ value \\
\hline \multicolumn{4}{|c|}{ Femoral neck $\mathbf{T}$ score } & \multirow{2}{*}{$0.0003^{*}$} \\
\hline Mean \pm SD & $-2.00 \pm 1.00$ & $-1.13 \pm 1.02$ & $-1.1 \pm 0.76$ & \\
\hline \multicolumn{4}{|c|}{ Lumbar spine (L1-L4) T score } & \multirow{2}{*}{$0.0002^{\#}$} \\
\hline Mean \pm SD & $-2.48 \pm 1.03$ & $-1.69 \pm 1.15$ & $-1.4 \pm 1.01$ & \\
\hline
\end{tabular}

*Statistically significant; "Statistically significant

$50 \%$ of women with normal BMI have osteoporosis whereas it was seen in only $15 \%$ of overweight and obese females. Normal BMD was found to be highest in the obese group (Figure 2).

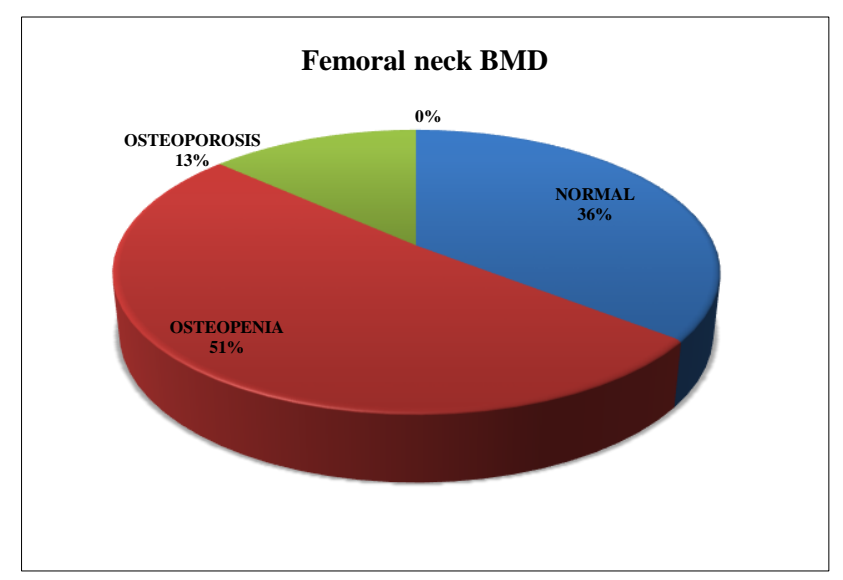

Figure 3: Distribution of bone mineral density femoral neck amongst all study subjects $(n=90)$.

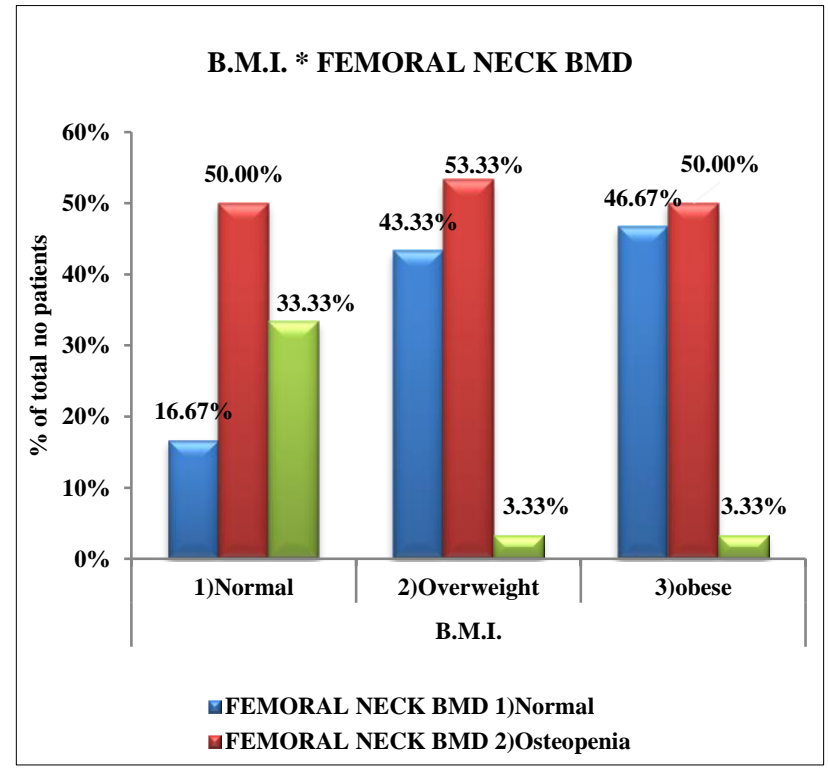

Figure 4: Graph depicting relationship of BMI and BMD at femoral neck. 
At femoral neck, $32(36 \%)$ females had T scores above $1.0,46(51 \%)$ females had T-scores between -1.0 and -2.5 and $12(13 \%)$ females had T-scores below -2.5 out of the total study subjects $(n=90)$ (Figure 3$)$. At femoral neck, the frequency of osteoporosis was $33.33 \%$ in females with normal BMI whereas it was $3.33 \%$ in females with BMI $>30 \mathrm{~kg} / \mathrm{m}^{2}$. Normal BMD was observed in $46.67 \%$ obese, $43.33 \%$ of overweight and only $16.67 \%$ of normal BMI postmenopausal females (Figure 4). The result was statistically significant $(\mathrm{p}=0.001)$ (Table 3$)$.

Table 5: Relationship of mean weight of postmenopausal females with BMD at lumbar spine and femoral neck.

\begin{tabular}{|lllll|}
\hline & BMID T score & & & \\
\hline Weight $(\mathbf{k g})$ Mean \pm SD & Normal & Osteopenia & Oestoporosis & P value \\
\hline At femoral neck & $70.82 \pm 9.4$ & $64.79 \pm 11.58$ & $52.03 \pm 6.55$ & $<0.0001^{*}$ \\
\hline At lumbar spine & $73.63 \pm 9.62$ & $65.23 \pm 9.55$ & $57.55 \pm 12.36$ & $<0.0001^{\#}$ \\
\hline
\end{tabular}

*Statistically significant; "Statistically significant

The observations in this study reveal that body mass index was associated with bone mineral density and this association was statistically significant. Obese postmenopausal females had a higher BMD at both lumbar spine and femoral neck than the females with normal BMI. However, BMD at femoral neck was higher than at lumbar spine across all three categories of BMI (Table 4).

Not only BMI but weight, as an independent variable was also found to be associated with BMD at both the sites and these results were statistically significant (Table 5).

\section{DISCUSSION}

The present study depicted the relationship of BMI and BMD amongst 90 healthy postmenopusal Indian women with a menopausal duration of 1-5 years. They were categorized according to their BMI into normal (BMI 18.5 to 24.9), overweight (25 to 29.9) and obese $\left(\geq 30 \mathrm{~kg} / \mathrm{m}^{2}\right)$. BMD at femoral neck and lumbar spine was observed across the three groups of BMI. Statistically significant association was found between body mass index and bone density. The mean T-score at femoral neck was $-2.00,-1.13$ and -1.1 in normal, overweight and obese females respectively $(p=0.0003)$. Mean BMD at lumbar spine was $-2.48,-1.69$ and -1.4 across all categories of BMI $(p<0.0002)$. Females in the obese group had higher BMD at both the sites than the ones with normal BMI.

BMD at lumbar spine was lower than that at femoral neck across all the three groups of BMI. Thus, we observed that BMI was significantly associated with BMD at both lumbar spine and femoral neck. Similar association between BMI and BMD was observed in several other studies.

A significant difference in the BMD at LS, FN and trochanter was found between normal and obese group of postmenopausal females by Henyse $\mathrm{G}$ et al in $2007 .{ }^{9}$ Ravn P and colleagues evaluated bone loss in 2 years in early postmenopausal females and its relationship with BMI. Low bone mass and increased bone loss was observed in women in the lowest tertile of body mass index. The females with least BMI had up to $12 \%$ lower bone mass at baseline and 2 fold higher rate of bone loss in 2 years $(p<0.004) .{ }^{10}$ Mendez et al observed the relationship of BMI and BMD in Mexican Mestizo postmenopausal females and found that a higher BMI is associated significantly and positively with a higher BMD at lumbar spine, femoral neck and total hip. ${ }^{11}$ The results were consistent with that of a study conducted by Shi Feng Wu in postmenopausal Chinese females. ${ }^{12}$ Kofi Asomaning concluded in their study that women with low BMI are at an increased risk of osteoporosis and the odds of bone loss decreased by $12 \%$ with each unit increase in BMI. ${ }^{13}$ Jain $\mathrm{V}$ et al concluded that after adjusting for age, chance of getting low BMD was $94 \%$ less in obese females when compared to females with normal BMI in Indian population. ${ }^{14}$

Significant positive correlation was observed between BMI and BMD in postmenopausal Pakistani females by Tariq $\mathrm{S}$ et al. ${ }^{15}$

Some authors have also reported no significant association between BMI and BMD. Bansal et al in 2017 evaluated 400 females, both pre and postmenopausal and did not find any significant correlation between BMI and BMD even in postmenopausal women. ${ }^{16}$ Compston JE conducted a multinational, prospective, observational population based study in 60,393 postmenopausal females of $>55$ years of age. They observed that Fracture prevalence in obese women at baseline was 222 per 1000 and incidence at 2 years was 61.7 per 1000 , similar to rates in non-obese women (227 and 66.0 per 1000 , respectively). The risk of incident ankle and upper leg fractures was significantly higher in obese than in nonobese women. Thus, they concluded that obesity is not protective against fracture in postmenopausal women and is associated with increased risk of ankle and upper leg fractures. $^{17}$ 


\section{CONCLUSION}

Low BMI may be a risk factor for the occurrence of low bone density. Body weight and BMI are important factors affecting BMD. The significance of body mass as a risk factor varies according to the level of BMI. Patient may be advised to maintain a normal body weight to prevent risk of osteopenia and osteoporosis. To substantiate future risk and optimize public health strategies like early osteoporosis prevention efforts, further studies should focus on the impact of various risk factors for osteoporosis including body mass index in postmenopausal women.

\section{ACKNOWLEDGMENTS}

Authors would like to express our heartfelt gratitude to all the patients who cooperated with us, the department of obstetrics and gynecology and radiology of PGIMER and Dr, RML hospital, New Delhi, India.

Funding: No funding sources

Conflict of interest: None declared

Ethical approval: The study was approved by the Institutional Ethics Committee

\section{REFERENCES}

1. Menopausal terminology. International Menopause Society, 2015. Available at: http://www.imsociety.org/menopause_terminology.p hp. Accessed on $8^{\text {th }}$ May 2018.

2. Pal A, Hande D, Khatri S. Assessment of menopausal symptoms in perimenopause and postmenopause women above 40 years in rural area. Int J Healthcare Biomed Res. 2013;1(3):166-74.

3. Unni J. Third consensus meeting of Indian Menopause Society (2008): A summary. J Mid-life Health. 2010;1(1):43-7.

4. Shatrugna V, Kulkarni B, Kumar P, Rani K, Balakrishna N. Bone status of Indian women from a low-income group and its relationship to the nutritional status. Osteoporosis Int. 2005;16(12):1827-35.

5. Nohara T, Kamei T, Ohta A. Accelerated decrease in bone mineral density in women aged 52-57 years. Tohoku J Exp Med. 2006;210(4):341-7.

6. Fritz M, Speroff L. Clinical Gynecologic Endocrinology and Infertility. $8^{\text {th }}$ ed. New Delhi: Wolters kluwer; 2011:714-720.

7. Krassas G, Papadopoulou P. Oestrogen action on bone cells. J Musculoskel Neuron Interact. 2001;2(2):143-51

8. Padubiri VG, Daftary SN. Perimenopause, menopause, premature menopause and postmenopausal bleeding. Howkins and Bourne Shaw's textbook of Gynecology. $15^{\text {th }}$ ed. New Delhi: Elsevier India pvt. Ltd.; 2011:1233-47.

9. Hensye G, Silva V, Mendonca L, Conceicao F, Zahar $\mathrm{S}$, Farias M. Influence of obesity on bone density in postmenopausal women. Arq Bras Endocrinol Metab. 2007;51(6):943-9.

10. Ravn P, Cizza G, Bjarnason N, Thompson D, Daley $\mathrm{M}$, Wasnich $\mathrm{R}$, et al. Low body mass index is an important risk factor for low bone mass and increased bone loss in early postmenopausal women. J Bone Mineral Res. 1999;14(9):1622-7.

11. Méndez J, Rojano-Mejía D, Pedraza J, CoralVázquez R, Soriano R, García-García E, et al. Bone mineral density in postmenopausal Mexican-Mestizo women with normal body mass index, overweight, or obesity. Menopause: The J North American Menopause Society. 2012;20(5):568-72.

12. $\mathrm{Wu} \mathrm{S}, \mathrm{Du} X$. Body mass index may positively correlate with bone mineral density oflumbar vertebra and femoral neck in postmenopausal females. Med Sci Monitor. 2016;22:145-51.

13. Asomaning $\mathrm{K}$, Bertone JE, Nasca $\mathrm{P}$, Hooven $\mathrm{F}$, Pekow $\mathrm{P}$. The association between body mass index and osteoporosis in patients referred for a bone mineral density examination. J Women's Health. 2006;15(9):1028-34.

14. Jain V. Prediction of bone mineral density by age, body mass index and menopausalstatus in middle socioeconomic status women of urban Kolar region of Bhopal. IOSR J Dent Med Sci. 2013;12(3):17-21.

15. Tariq S, Tariq S, Khalid PL. Relationship of anthropometric measures with bonemineral density in postmenopausal non-osteoporotic, osteopenic and osteoporotic women. J Pakistan Med Asso. 2017;67(4):590-4.

16. Bansal S, Bansal A. Relation between obesity and osteoporosis in Women. Int $\mathrm{J}$ Med Dent Sci. 2017;6(1):1382-5.

17. Compston J, Watts N, Chapurlat R, Cooper C, Boonen S, Greenspan S, et al. Obesity is not protective against fracture in postmenopausal women: GLOW. The Am J Med. 2011;124(11):1043-50.

Cite this article as: Goyal A, Malla VG.

Relationship of body mass index with bone mineral density in postmenopausal women: an Indian perspective. Int J Reprod Contracept Obstet Gynecol 2019;8:4490-5. 